\title{
Comparison of CYP1A2 and NAT2 phenotypes between black and white smokers
}

\author{
Joshua E. Muscat ${ }^{a}$, Brian Pittman ${ }^{b}$, Wayne Kleinman ${ }^{c}$, Philip Lazarus ${ }^{d}$, \\ Steven D. Stellman ${ }^{e}$, John P. Richie Jr. ${ }^{a, *}$
}

a Penn State Cancer Institute, Department of Public Health Sciences, Penn State University College of Medicine, Hershey, PA 17036, United States

${ }^{\mathrm{b}}$ Yale University School of Medicine, New Haven, CT 06510, United States

${ }^{\mathrm{c}}$ Department of Neurology and Neuroscience, Cornell University Medical Center, Burke Medical Research Institute, White Plains, NY 10605, United States

d Penn State Cancer Institute, Department of Pharmacology, Penn State University College of Medicine, Hershey, PA 17036, United States

e Department of Epidemiology, Mailman School of Public Health, Columbia University, New York, NY, United States

\section{A R T I C L E I N F O}

Article history:

Received 16 June 2008

Accepted 16 July 2008

\section{Keywords:}

Bladder

Cancer

Smoking

Acetylation

Cytochrome P450

Caffeine

\begin{abstract}
A B S T R A C T
The lower incidence rate of transitional cell carcinoma of the urinary bladder in blacks than in whites may be due to racial differences in the catalytic activity of enzymes that metabolize carcinogenic arylamines in tobacco smoke. To examine this, we compared cytochrome P4501A2 (CYP1A2) and N-acetyltransferase-2 activities (NAT2) in black and white smokers using urinary caffeine metabolites as a probe for enzyme activity in a community-based study of 165 black and 183 white cigarette smokers. The paraxanthine (1,7-dimethylxanthine, 17X)/caffeine (trimethylxanthine, 137X) ratio or [17X + 1,7-dimethyluric acid (17U)]/137X ratio was used as an indicator of CYP1A2 activity. The 5-acetyl-amino6-formylamino-3-methyluracil (AFMU)/1-methylxanthine (1X) ratio indicated NAT2 activity. The odds ratio for the slow NAT2 phenotype associated with black race was $0.4 ; 95 \%$ confidence intervals $0.2-0.7$. The putative combined low risk phenotype (slow CYP1A2/rapid NAT2) was more common in blacks than in whites $(25 \%$ vs. $15 \%, P<0.02)$. There were no significant racial differences in slow and rapid CYP1A2 phenotypes, and in the combined slow NAT2/rapid CYP1A2 phenotype. Age, education, cigarette smoking amount, body mass index, GSTM1 and GSTM3 genotypes were unrelated to CYP1A2 and NAT2 activity. Intake of cruciferous vegetables (primarily broccoli), red meat, carrots, grapefruit and onions predicted CYP1A2 activity either for all subjects or in race-specific analyses. Carrot and grapefruit consumption was related to NAT2 activity. Collectively, these results indicated that phenotypic differences in NAT2 alone or in combination with CYP1A2 might help explain the higher incidence rates of transitional cell bladder cancer in whites.
\end{abstract}

(C) 2008 Elsevier Inc. All rights reserved.

* Corresponding author at: Penn State Cancer Institute, Division of Population Sciences, Department of Public Health Sciences, Penn State University College of Medicine, H069, 500 University Drive, Hershey, PA 17033, United States. Tel.: +1 7175315381 ; fax: +1 7175310480. E-mail address: jrichie@psu.edu (J.P. Richie Jr.).

Abbreviations: CYP1A2, cytochrome P4501A2; NAT2, N-acetyltransferase-2; 17X, paraxanthine (1,7-dimethylxanthine); 137X, caffeine (trimethylxanthine); 17U, 1,7-dimethyluric acid; 4-ABP, 4-aminobiphenyl; AFMU, 5-acetyl-amino-6-formylamino-3-methyluracil; 1X, 1methylxanthine; GSTM1, glutathione transferase M1; GSTM3, glutathione transferase M3; HPLC, high performance liquid chromatography; cpd, cigarettes smoked per day; OR, odds ratio; CI, confidence interval; POR, proportional odds ratio. 0006-2952/\$ - see front matter (C) 2008 Elsevier Inc. All rights reserved. 


\section{Introduction}

Bladder cancer is the fourth most commonly diagnosed cancer in men and eighth most common in women in the United States. The incidence rates of transitional cell carcinoma, which account for the majority of bladder tumors, are approximately twice as high in white men vs. black men and 1.5 times higher in white women than in black women [1]. Squamous cell carcinoma of the bladder is rare but higher in blacks than in whites [2]. Tobacco smoke contains arylamines, which are a known class of bladder carcinogens and thought to be the likely causative agent responsible for the increased risk of bladder cancer in cigarette smokers [3,4]. The major route for arylamine activation to reactive electrophiles involves N-hydroxylation by cytochrome P4501A2 (CYP1A2) [5]. The detoxification pathway occurs via $\mathrm{N}$-acetylation by $\mathrm{N}$ acetyltransferase-2 (NAT2) [6]. Differences in the activity of these enzymatic pathways may affect the risk for bladder cancer as the slow acetylation phenotype and polymorphisms in NAT2 genes have been linked with increased levels of 4aminobiphenyl (4-ABP)-hemoglobin adducts in smokers and with increased risk for bladder cancer $[7,8]$.

The urinary ratios of caffeine metabolites (Fig. 1) are commonly used as a probe for the in vivo phenotyping of CYP1A2 [5]. Approximately 95\% of the primary systematic clearance of caffeine has been attributed to CYP1A2 activity [9]. Twin studies indicate that most of the wide variation in CYP1A2 activity is determined by genetic factors [10]. However among the $>25$ single nucleotide polymorphisms in CYP1A2 that have been identified (www.imm.ki.se/CYPalleles), few have been associated with altered function. The CYP1A2*1C and CYP1A2*1F polymorphisms have been associated with decreased enzyme inducibility in smokers [11,12]. CYP1A2 activity is also induced or affected by cigarette smoking, diet, and environmental factors [13-15]. Some data indicate that activity levels may vary by race or ethnicity. In children, mean urinary caffeine metabolite ratios were higher in whites than

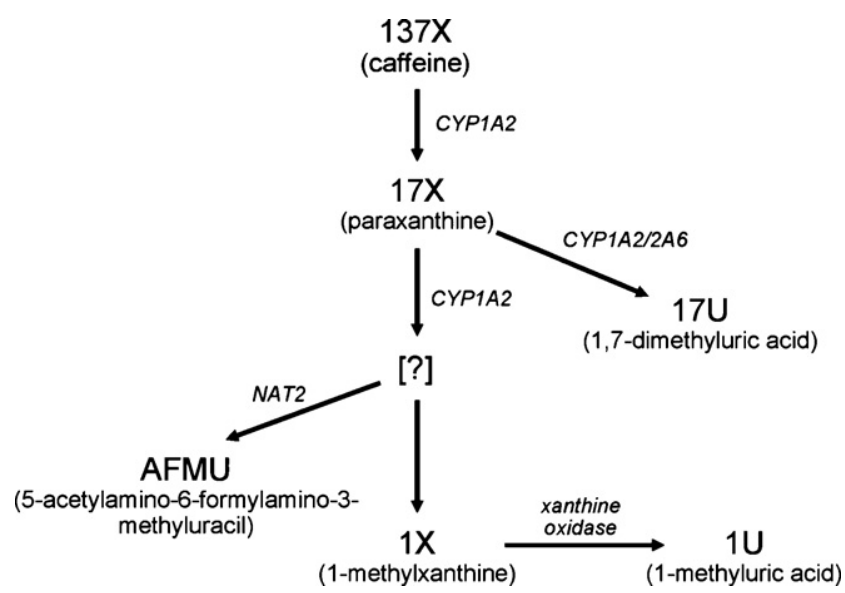

Fig. 1 - Simplified scheme for caffeine metabolism. CYP1A2 catalyzes the 3-demethylation of caffeine (137-X) to paraxanthine (PX; 1,7,DMU) and NAT2 catalyzes the acetylation of PX metabolites to 5-acetyl-amino-6formylamino-3-methyluracil (AFMU). The "?" refers to a postulated intermediate. This figure was adapted from Grant et al. [19]. in blacks [16]. In contrast theophylline clearance was higher in blacks than in whites and latinos [17], and propranolol 4hydroxylase activity in liver microsomal specimens was higher in samples obtained from black surgical patients than from white patients [18].

Measurement of caffeine metabolites has also been used for the assessment of NAT2 activity (acetylation phenotype), as the formation of 5-acetylamino-6-formylamino-3-methyluracil (AFMU) from caffeine is principally catalyzed by the non-inducible NAT2 (Fig. 1) [19,20]. Genetic polymorphisms in the NAT2 gene are predictive of bladder cancer [21]. They are also correlated with the NAT2 activity, explaining about half of the variance in the distribution of the AFMU/1X phenotype [22-24]. However there is little data on racial differences in the NAT2 phenotype. The slow isoniazid acetylation phenotype was more common in black American and African tuberculosis patients than in white patients $[25,26]$. Other data indicate similar isoniazid acetylation phenotype prevalences between white and black Americans [27,28]. The slow sulphamethazine acetylation phenotype was more prevalent in Nigerian than in various Caucasian subjects [29-35]. The slow NAT2 genotype was reported to be more common in whites than in black South Africans [36].

Utilizing the measurement of urinary caffeine metabolites to assess metabolic phenotype for CYP1A2 activation and NAT2 detoxification pathways [37-39], we sought to determine if racial differences in the biochemical activation or detoxification of arylamines might contribute to the higher incidence rates of bladder cancer in whites than in blacks. Thus, the current study compares the CYP1A2, NAT2 and their combined phenotypes in a large group of black and white adult smokers. Since polymorphisms in glutathione transferases (GST), including GSTM1-null, together with slow acetylation phenotype have been linked with increased risk of bladder cancer [40-43] and GSTM1 null genotype was associated with enhanced 4-ABP hemoglobin adducts [44], we also examined the effects of GSTM polymorphisms on CYP1A2 and NAT2 activity.

\section{Materials and methods}

\subsection{Materials}

Caffeine (137X) and its metabolites 1,7-dimethylxanthine (17X), 1-methylxanthine (1X), 1,7-dimethyluric acid (17U), and 1-methyluric acid (1U) were obtained from Sigma Chemical Co. (St. Louis, MO). 5-Acetylamino-6-formylamino3-methyluracil was obtained from Dr. B.K. Tang at the University of Toronto. All other reagents were obtained from Sigma Chemical Co. (St. Louis, MO) unless otherwise indicated.

\subsection{Subjects and study design}

There were 348 (165 non-Hispanic black and 183 white) current cigarette smokers who participated in the caffeine testing, as part of a larger study of over 600 subjects recruited for studies of smoking biomarkers. The subjects were recruited from Mount Vernon, Yonkers and other areas in southeastern Westchester County, NY $[45,46]$. Smokeless tobacco, pipe and 
cigar users were ineligible to participate. Mt. Vernon is a racially diverse middle-income community of $\sim 65,000$ residents. The recruitment methods included fliers, public lectures, newspapers advertisements, and word of mouth. All subjects signed a written informed consent approved by the Institutional Review Board of the Institute for Cancer Prevention, and refrained from caffeine intake for $24 \mathrm{~h}$ before sample collection. We collected an early morning urine sample from each subject, and at approximately 9 a.m. the subjects were provided an 8-oz. cup of hot water containing 2 tablespoons of instant coffee. The beverage was consumed in its entirety within $10 \mathrm{~min}$. Additional urine specimens were collected 3 and $4 \mathrm{~h}$ after the morning sample and were immediately frozen and stored at $-20^{\circ} \mathrm{C}$.

\subsection{Questionnaire}

We interviewed each subject using a structured questionnaire that contained items on demographics and lifestyle factors such as number of cigarettes smoked per day (cpd). Usual food intake was assessed using a validated food frequency questionnaire [47].

\subsection{Determination of CYP1A2 and NAT2 phenotypes by caffeine metabolites}

In the $4 \mathrm{~h}$ urine samples, we measured caffeine and its metabolites 17X, 1X, 17U, 1U, and AFMU [13,35-37]. The frozen urine samples were thawed at room temperature and adjusted to $\mathrm{pH} 3.5$ with $\mathrm{HCl}$. Aliquots $(200 \mu \mathrm{l})$ were saturated with $120 \mathrm{mg}$ of ammonium sulfate. After addition of $200 \mu \mathrm{l}$ of internal standard $(120 \mu \mathrm{g} / \mathrm{ml} \mathrm{4-acetamidophenol} \mathrm{in} \mathrm{chloro-}$ form) $6 \mathrm{ml}$ of chloroform:isopropanol (19:1) was added. After centrifugation at $3000 \times g$ for $5 \mathrm{~min}$, about $5.5 \mathrm{ml}$ of the organic phase was removed and evaporated to dryness at $42{ }^{\circ} \mathrm{C}$ under nitrogen. Samples were resuspended in $1 \mathrm{ml}$ of $0.05 \%$ acetic acid and filtered through a $0.22-\mu \mathrm{m}$ syringe filter.

High performance liquid chromatography (HPLC) was performed by separating the metabolites using a reversedphase $4.6 \mathrm{~mm} \times 250 \mathrm{~mm}$ column (Inertsil ODS-3, GL Sciences, Inc., Torrance, CA) and eluted with mobile phases A $(0.045 \%$ acetic acid and 9\% methanol) and B (100\% methanol) using a gradient profile starting at $10 \% \mathrm{~B}$ to $16.5 \mathrm{~min}$, increasing to $20 \%$ B from 16.5 to $19.8 \mathrm{~min}$ and continuing at $20 \%$ B for $27 \mathrm{~min}$. A $5 \mathrm{~min}$ washout period with $100 \%$ B and a 15 min reequilibration period with $10 \% \mathrm{~B}$ was used between samples. The standards included AFMU, 1U, 1X, 17U, 17X, 137X, and internal standard. Spectral conformation of caffeine metabolite peaks was performed routinely, using a programmable multiple wavelength detector (Waters 490E, Waters Corp., Milford, MA). Using this methodology, recovery of caffeine, paraxanthine, AFMU and 1-methylxanthine ranged from 91 to $103 \%$.

Caffeine 3-demethylation activity (CYP1A2) was assessed by determining the ratio $(17 \mathrm{X}+17 \mathrm{U}) / 137 \mathrm{X}$, as described previously [20]. Use of this molar ratio was based upon its high correlation ( $r=0.73$ ) with the rate constant for hepatic 3demethylation of caffeine in a pharmacokinetic study (calculated as the ratio of rate constants for the hepatic conversion of caffeine to paraxanthine and the excretion of caffeine into urine) [20]. This ratio typically falls into three phenotypes (slow, intermediate or fast). Both CYP1A2 and CYP2A6 are involved in the 7-demethylation of 17X with the later playing the principal role [48]. In addition, the ratio 17X/ $137 \mathrm{X}$ was also assessed as originally described [49] which typically yields two phenotype (slow and fast). Since previous caffeine phenotyping studies measured enzyme activity either by area or molar ratios, both measures were calculated and compared in the present study. The frequency distribution of $(17 \mathrm{X}+17 \mathrm{U}) / 137 \mathrm{X}$ in our data indicated a trimodal distribution, with cut points that represented 10\% (slow), 54\% (intermediate) and $37 \%$ (rapid) of the distribution. The distribution of $17 \mathrm{X} / 137 \mathrm{X}$ was bimodal with a cut point of 1.85 separating slow and rapid phenotypes. The cut point was confirmed by examination of a 17X/137X probit plot. About $75 \%$ of subjects were classified as slow activators based on 17X/137X levels.

In 279 subjects (122 blacks and 170 whites), CYP1A2 phenotype was calculated by both peak area and molar ratios. The correlation between peak areas and molar determinations was 0.99 for $(17 \mathrm{X}+17 \mathrm{U} / 137 \mathrm{X})$ and 0.96 for $(17 \mathrm{X} / 137 \mathrm{X})$. We therefore report the findings based on peak area ratios since these values were determined for all subjects.

The ratio of AFMU/1-methylxanthine was calculated to measure acetylation phenotype (NAT2 activity). The activity levels were not measured for a few samples because of the presence of interfering urinary constituents that co-migrate with caffeine on HPLC in those samples. Subjects were classified as slow and rapid acetylators based on the distribution of these values. The variation of the analytical method was assessed by an analysis of control samples. The overall variation (CV) for control values (long-term assay CV) were $7.3,8.4,11.4,9.7$ and $12.1 \%$ for $137 \mathrm{X}, 17 \mathrm{U}, 17 \mathrm{X}, 1 \mathrm{X}$ and AFMU, respectively.

\begin{tabular}{|c|c|c|c|c|c|}
\hline Smoking history & $n$ & Blacks $^{a}$ & $n$ & Whites $^{\mathrm{a}}$ & $P$-value \\
\hline Age started & 165 & $16.7 \pm 4.1$ & 183 & $16.1 \pm 3.8$ & 0.15 \\
\hline Years of smoking & 165 & $17.3 \pm 8.1$ & 184 & $16.4 \pm 10.2$ & 0.35 \\
\hline Cigarettes per day & 165 & $14.2 \pm 8.1$ & 185 & $22.3 \pm 11.1$ & $<0.01$ \\
\hline \multicolumn{6}{|l|}{ Menthol status } \\
\hline Mentholated (\%) & 138 & 83.6 & 42 & 23.0 & $<0.01$ \\
\hline Non-mentholated (\%) & 27 & 16.4 & 141 & 77.0 & \\
\hline
\end{tabular}




\subsection{Determination of urinary cotinine and creatinine}

ELISA (OraSure Technologies, Inc., Bethlehem, PA) was performed to quantify levels of urinary cotinine in the morning void sample. A Vitros Ektachem 500 clinical chemistry analyzer (Ortho Clinical Diagnostics of Johnson \& Johnson, Rochester, NY) was used to measure urinary creatinine levels in the same sample.

\subsection{Determination of GSTM1 and GSTM3 genotypes}

The GSTM3 intron 6 polymorphism was determined in a subset of 216 subjects by restriction fragment length polymorphism analysis using exon 6/exon 7 primers (5'-CCTCAGTACTTGGAAGAGCT-3'; 5'-CACATGAAAGCCTTCAGGTT-3') and MnlI digestion using methods previously described [50]. The presence of the GSTM1 null polymorphism was determined using a 3-primer-based PCR assay as previously described [50].

\subsection{Statistical analysis}

Means, standard deviations, ranges, and frequency distributions were calculated to summarize the data. We determined the normality of the distributions using the KolomogorovSmirnov test and visual examination of frequency plots. The Student's t-test compared descriptive data and caffeine ratios between blacks and whites. Pearson correlations were calculated to determine the association between the peak AUC and the molar ratio. Pearson correlation coefficients were calculated between potential predictors of enzyme activity levels, such as age and smoking amount, and the logtransformed values of the CYP1A2 and NAT2 ratios. Caffeine phenotype categories were defined as slow vs. rapid activators and slow vs. rapid acetylators. The combined phenotypes were classified as slow NAT2/slow CYP1A2, slow NAT2/rapid CYP1A2 (the putative highest risk group), rapid NAT2/slow CYP1A2 (the putative lowest risk group) and rapid NAT2/rapid CYP1A2. We conducted unconditional logistic regression analyses to test the association between phenotype category and race using SAS statistical software (Version 8.2, Cary, NC). A forward selection method was used for the logistic models using an entry probability criterion of 0.25 . The covariates included sex, age, education, and smoking amount (e.g. ratio of urinary cotinine-to-creatinine per $\mathrm{dl}$, or alternatively smoking amount categorized as 5-9, 10-19, 20-29, 30-39 and $\geq 40 \mathrm{cpd}$ ). The proportional odds model was fitted for the trimodal CYP1A2 phenotype by assigning the values into three ordinal categories ( 1 =slow, 2 = intermediate and $3=$ rapid). The proportional odds assumption and the fit of the logistic regression models were tested by the Score and HosmerLemeshow tests, respectively. Chi-square tests were calculated to determine proportional differences in combined CYP1A2/NAT2 phenotypes by race. Sample sizes for these different analyses varied as data on CYP activity was missing for 1 subject, data on acetylation activity was missing for 18 subjects, and 19 subjects had a missing value either for CYP or NAT2.

In exploratory analyses, forward stepwise regression was conducted to determine the effects of food items on the logtransformed CYP $(17 \mathrm{U}+17 \mathrm{X} / 137 \mathrm{X})$ and NAT2 phenotypic

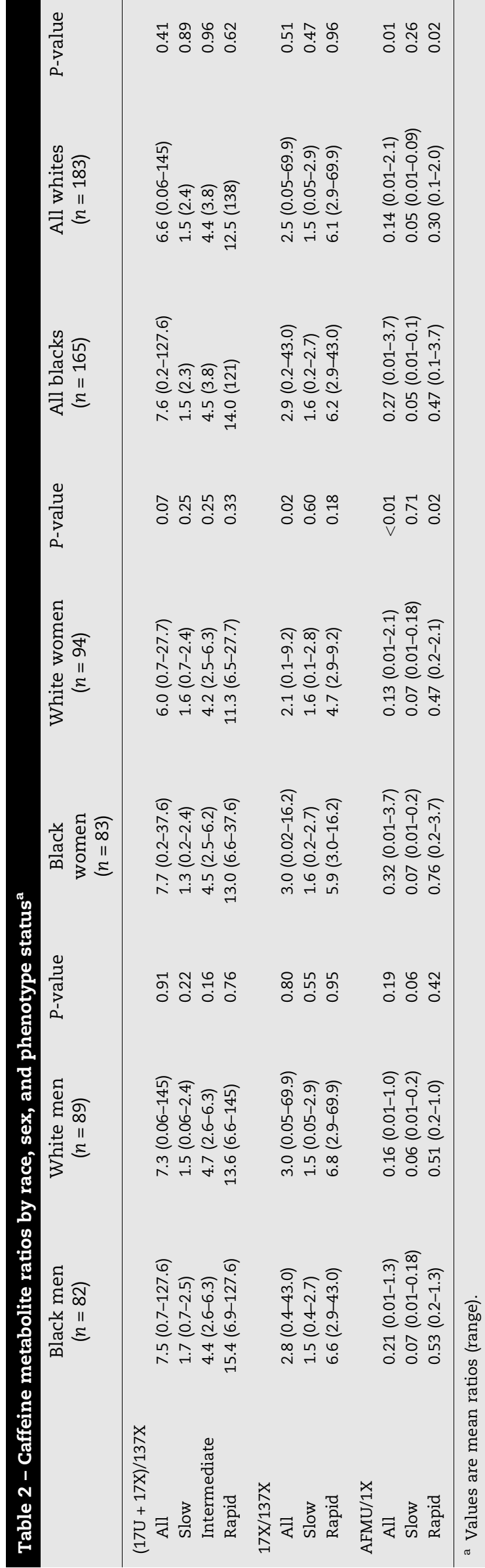


ratios. The foods included cruciferous vegetables (broccoli, cabbage), onions, carrots, red meat (beef, pork), cured meats (ham, hot dog, bacon, sausage), fish, tomatoes/tomato juice, total fruit/fruit juice consumption, and high fiber breads and cereals. Except for total fruit consumption, the distribution of dietary intake was not normally distributed and tended to be multimodal. Consequently food items were grouped into three frequency categories and assigned the median value of intake for each group. The model entry criterion was set at a liberal $0.45 \mathrm{P}$-value. All P-values were two-sided and considered significant at $<0.05$.

\section{Results}

The subjects included 82 black men, 83 black women, 89 white men and 94 white women. The mean age was 34.8 in blacks and 33.2 in whites, and the age of smoking onset and total years of smoking were similar between blacks and whites (Table 1). The mean daily cigarette intake was 14.2 in blacks and 22.3 in whites. More blacks than whites smoked mentholated cigarettes ( $83.6 \%$ vs. $23.0 \%, P<0.01$ ). AFMU/1X values were determined for 330 subjects.

The correlation coefficients for age, body mass index and cigarettes per day with CYP1A2 measures in all subjects were all $\leq|0.13|$. Similarly, the correlation coefficients for age, education, BMI and cpd with NAT were $\leq|0.14|$. The correlation coefficients between the GST genotypes and CYP1A2 and NAT2 phenotypes were $\leq|0.09|$. In race specific analysis, the correlation between GSTM1 null genotype and acetylation phenotype was $0.16(P<0.13)$ in whites, and the correlation between the GSTM3 genotype and acetylation phenotype was $0.18(P<0.09)$.

The mean values and the ranges for the caffeine metabolite ratios are presented in Table 2 by race, sex and phenotype categories. There were no significant differences in mean $(17 \mathrm{X}+17 \mathrm{U} / 137 \mathrm{X})$ values between white and black men. The mean ratio was 7.7 in black women and 6.0 in white women $(P=0.07)$. The mean ratio of $17 X / 137 X$ was similar for black and white men, and higher in black vs. white women (3.0 vs. 2.1, $P=0.02$ ). The mean ratio for AFMU/1X was 0.21 in black men and 0.16 in white men $(P=0.18)$, and 0.32 in black women and 0.13 in white women $(P<0.01)$. In rapid acetylators, the values were 0.51 for black women and 0.25 for white women $(P=0.02)$. The prevalence of the putative high risk GSTM1 null genotype was substantially greater in whites $(45.3 \%)$ than in blacks
(18.5\%). The prevalence of the GSTM3*B homozygous genotype consisting of a 3-bp deletion in intron 6 of the GSTM3 gene which has been postulated to increase GSTM3 transcription [51] and has been linked to decreased risk for certain cancers $[51,52]$ was greater in blacks $(37 \%)$ than in whites $(1.9 \%)$.

The odds ratio for the slow CYP activation (17X/137X) phenotype associated with black race was $0.74 ; 95 \%$ CI $0.5-1.2$ (Table 3). None of the covariates tested were associated with the activation phenotype. Sex-specific odds ratios were also not statistically significant. The proportional odds ratio for the (slow vs. intermediate vs. rapid) CYP1A2 ([17U + 17X]/137X) activation phenotype associated with black race was $0.8 ; 95 \%$ CI 0.6-1.2. The proportional odds assumption was validated by Chi-square analysis $(P=0.84)$.

The mean AFMU/1X ratio was higher in blacks than in whites $(0.27 \pm 0.47$ vs. $0.14 \pm 0.23, P<0.01$; Table 2$)$. More blacks than whites were classified as rapid acetylators (64\% vs. $36 \% ; P<0.05$, Table 3). The odds ratio for the slow NAT phenotype associated with black race was $0.4 ; 95 \%$ CI $0.2-0.7$ (Table 3). The cotinine-to-creatinine ratio was associated with slow acetylation $(P=0.09)$. Using reported cigarettes smoked per day as an alternative measure to cotinine, only smoking $\geq 2$ packs $(40 \mathrm{cpd})$ vs. $<10 \mathrm{cpd}$ was associated with the slow acetylation phenotype $(P=0.04)$.

There were significant racial differences in the prevalence of the combined CYP1A2/NAT2 phenotypes (Table 4). There were significantly more blacks than whites in the putative lowest risk category, e.g. slow CYP1A2 (17X/137X)/rapid NAT2 phenotype $(24.4 \%$ vs. $14.8 \%, P<0.02)$ compared to the other three combined phenotypes. The sex-specific findings for the slow CYP1A2 (17X/137X)/rapid NAT2 phenotype were similar ( $22.7 \%$ vs. $16.8 \%$ in men and $27.5 \%$ vs. $13.0 \%$ in women). There were no significant racial differences in the proportion of the putative highest risk phenotype, e.g. the rapid CYP1A2 (17X/ $137 \mathrm{X})$ /slow NAT2 group ( $20.6 \%$ vs. $21.9 \%$ ) compared to the other three phenotypes combined. Similar results were found for the combined $(17 \mathrm{X}+17 \mathrm{U} / 137 \mathrm{X})$ and NAT2 phenotypes (Table 4).

In stepwise regression analysis examining dietary intake, cruciferous vegetable and red meat intake were significant predictors of CYP1A2 activity (Table 5). When stratified by race, carrot and onion consumption were predictors of CYP1A2 activity while grapefruit consumption was inversely related to CYP1A2 activity. There were no significant dietary predictors in black subjects. There were no significant dietary predictors of NAT2 activity, although marginal associations were

\begin{tabular}{|c|c|c|c|c|c|c|c|c|c|c|c|c|c|}
\hline \multirow[t]{2}{*}{ Race } & \multicolumn{2}{|c|}{ NAT2 $(\text { AFMU/1X) })^{a}$} & \multirow[t]{2}{*}{ OR } & \multirow[t]{2}{*}{$95 \%$ CI } & \multicolumn{2}{|c|}{$\begin{array}{c}\text { CYP1A2 } \\
(17 X / 137 X)^{a}\end{array}$} & \multirow[t]{2}{*}{ OR } & \multirow[t]{2}{*}{$95 \%$ CI } & \multicolumn{3}{|c|}{ CYP1A2 $(17 X+17 U) / 137 X^{a}$} & \multirow[t]{2}{*}{ POR } & \multirow[t]{2}{*}{$95 \% \mathrm{CI}$} \\
\hline & Slow & Rapid & & & Slow & Rapid & & & Slow & Intermediate & Rapid & & \\
\hline Whites & $140(56)$ & 29 (36) & 1.0 & & $142(55)$ & $41(47)$ & 1.0 & & 35 (56) & $86(54)$ & $62(50)$ & 1.0 & \\
\hline Blacks & $109(44)$ & $52(64)$ & 0.4 & $0.2,0.7$ & $118(45)$ & $46(53)$ & 0.74 & $0.5-1.2$ & $28(44)$ & $73(46)$ & $63(50)$ & 0.8 & $0.6,1.3$ \\
\hline
\end{tabular}

Abbreviations: $\mathrm{OR}=$ odds ratio. $\mathrm{CI}=$ confidence intervals, $\mathrm{POR}=$ proportional odds ratio. Models for AFMU/1X and 17X/137X are adjusted for age, education, sex and urinary cotinine/creatinine. Sample sizes for whites is one less than that listed in Table 2 for both NAT2 and CYP1A2 due to missing values for covariates. The model for $(17 \mathrm{X}+17 \mathrm{U}) / 137 \mathrm{X}$ is unadjusted for confounders.

${ }^{a}$ Values are number (\%). 
Table 4 - Combined CYP1A2 and NAT2 phenotypes in

black and white smokers

\begin{tabular}{lccc} 
Phenotype & Blacks $n(\%)$ & Whites $n(\%)$ & P-value \\
\hline CYP1A2 (17X/137X)/NAT2 & & & \\
Slow/slow & $76(47.5)$ & $103(61.0)$ & $<0.02$ \\
Slow/rapid & $39(24.4)$ & $25(14.8)$ & \\
Rapid/slow & $33(20.6)$ & $37(21.9)$ & \\
Rapid/rapid & $12(7.5)$ & $4(2.4)$ & \\
CYP1A2 [(17X + 17U)/137X]/NAT2 & & \\
Slow/slow & $13(8.1)$ & $22(13.0)$ & $<0.02$ \\
Slow/rapid & $14(8.8)$ & $4(2.4)$ & \\
Intermediate/slow & $53(33.1)$ & $64(37.9)$ & \\
Intermediate/rapid & $18(11.2)$ & $17(10.1)$ & \\
Rapid/slow & $43(26.9)$ & $54(32.0)$ & \\
Rapid/rapid & $19(11.9)$ & $8(4.7)$ & \\
\hline &
\end{tabular}

observed with cruciferous vegetable intake and carrot consumption (Table 5). When stratified by race, there was a significant association with grapefruit consumption in whites. There were no significant predictors in blacks.

\section{Discussion}

The phenotypic characterization of CYP1A2 can be subjective, with as many as $50 \%$ of subjects classified as rapid activators. Butler et al. [20] reported a trimodal distribution $(17 \mathrm{X}+17 \mathrm{U}) /$ $137 \mathrm{X}$ in a number of different populations of 12-13\% slow, 51$67 \%$ intermediate, and $20-37 \%$ rapid. This was similar to our trimodal distribution (10\%, 54\% and 37\%). The bimodal distribution of $17 \mathrm{X} / 137 \mathrm{X}$ indicated that about $30 \%$ of our subjects were rapid activators, which was similar to findings reported elsewhere [16].

We found that the slow acetylation phenotype was more highly prevalent in white than in black study participants regardless of gender, which is consistent with previous reports based on caffeine testing [16,32]. The percent of slow acetylators in white study subjects in this study was $51 \%$, slightly higher than that observed (45\%) in a pooled genotyping analysis [53]. Higher AFMU/1X molecular ratio values were observed in blacks compared to whites $(P<0.01)$ although this difference was primarily observed among rapid acetylators. In addition, 11 of the 12 subjects with the highest acetylation activity levels were black. Altogether, these results suggest that $\mathrm{N}$-acetylation activity is greater in blacks compared to whites. A possible mechanism for these phenotypic differences may likely involve racial differences in the distribution of NAT2 genotypes as previous studies indicate a greater prevalence of NAT2 genotypes associated with rapid acetylation among blacks compared to whites [54]. In our data, no associations with the NAT2 phenotype were found with age, sex, education, BMI, and cigarettes per day. Other investigations have also found that sociodemographic and lifestyle factors are unrelated to acetylation levels [24,55-57]. Our data did show an association between heavy smoking ( $\geq 40 \mathrm{cpd}$ ) and the slow acetylation phenotype, but this finding is possibly due to residual confounding by race as nearly all heavy smokers were white study subjects, who had lower acetylation activity.

There were no differences in mean CYP1A2 activity between blacks and whites. The caffeine ratios for CYP1A2 were lower in white women than in white men, which is consistent with previous reports $[16,58,59]$, although no sex differences were found in a controlled dietary trial [60]. There were no differences in the mean CYP1A2 caffeine ratios between black women and black men. However, the putative low risk combined slow CYP1A2/rapid NAT2 phenotype was more common in blacks than in whites.

The effects of specific dietary items on CYP1A2 activity has received little attention. Detecting such associations in a typical American diet is difficult because of the well known limitations in dietary recall and the ability to accurately quantify dietary intake by food frequency questionnaires. The effect size of any specific dietary item on a biomarker may also be small, and the frequency of specific food items is often highly correlated with other foods within food groups. In addition, multiple comparisons and analysis done in subgroups increase the likelihood of type I error and decrease statistical power, respectively. Despite these limitations, we found that CYP1A2 activity was weakly correlated with cruciferous vegetable intake. While there is little data supporting a protective role for vegetable intake on bladder cancer risk, recent data indicate that broccoli sprout extracts inhibit bladder cancer development in rats in a dose-dependent manner [61]. Our findings are consistent with the finding that brassica (cruciferous) vegetables increased and apiaceous vegetables decreased CYP1A2 activity relative to a vegetable-free diet in a four-arm randomized crossover dietary trial [59]. In another study of nine healthy volunteers, daily intake of $500 \mathrm{~g}$ of broccoli for 10 days increased CYP1A2 activity by $12 \%$ compared to a control group [62]. Our finding for cruciferous vegetables

\begin{tabular}{|c|c|c|c|c|c|c|}
\hline \multirow[t]{2}{*}{ Dietary item } & \multicolumn{3}{|c|}{ CYP1A2 } & \multicolumn{3}{|c|}{ Acetylation } \\
\hline & Partial $r$ & $P$-value & Model $r^{2}$ & Partial $r$ & $P$-value & Model $r^{2}$ \\
\hline Cruciferous vegetables & 0.11 & 0.01 & 0.034 & 0.03 & 0.09 & 0.02 \\
\hline Red meat & 0.12 & 0.01 & & & & \\
\hline Carrots & $0.18^{\mathrm{a}}$ & 0.01 & & -0.13 & 0.06 & \\
\hline Grapefruit & $-0.17^{\mathrm{a}}$ & 0.02 & & $0.04^{\mathrm{a}}$ & 0.02 & \\
\hline Onions & $0.13^{\mathrm{a}}$ & 0.03 & & & & \\
\hline
\end{tabular}

${ }^{a}$ Value is for white subjects only. 
(primarily broccoli) is also consistent with findings of frequent consumption associated with increased CYP1A2 activity in a Los Angeles-based study [63] where the effect was limited to subjects with the GSTM1 null genotype. However, we found no effect of cruciferous vegetable consumption when stratifying by GSTM1 genotype. The mechanism for CYP1A2 induction by cruciferous vegetable intake is unknown. While isothiocyanates derived from cruciferous vegetables are potent inducers of numerous phase II detoxification enzymes through a mechanism involving enhancement of the redox sensitive transcription factor Nrf2, there have been no reports of a possible role of nrf2 in regulating $P 450$ isozymes other than CYP2A5 [64]. In addition, other laboratory studies demonstrated an inhibitory effect of Isothiocyanates on CYP1A2 activity [65].

In our data, grapefruit consumption inhibited both CYP1A2 and acetylation activity in whites, however, we did not have information on grapefruit juice intake. This effect on CYP1A2 is consistent with in vitro data [66]. To our knowledge, there have been no previous reports on grapefruit juice and acetylation activity, however, in 90 Hawaiians of various ethnic backgrounds, cruciferous vegetable intake was unrelated to acetylation activity [24]. While NAT2 is not thought to be an inducible enzyme, associations with grapefruit intake could be facilitated through potential effects of grapefruit juice on the excretion of caffeine metabolites.

GST polymorphisms have been linked with bladder cancer risk [41-43] and in one study GSTM1 null genotype was linked with enhanced 4-ABP adduct formation suggesting that it may contribute to racial variation in 4-ABP metabolism and bladder cancer risk [44]. However, other studies found no associations between GST activity and 4-ABP metabolism [67]. In the present study, no associations between GSTM1 and GSTM3 genotype and NAT2 or CYP1A2 was observed. Higher prevalence of putative higher risk genotypes of both GSTM1 and GSTM3 in whites than in blacks were similar to those observed previously $[44,50]$.

The reasons why whites have higher rates of bladder cancer are not fully understood, particularly since blacks have higher rates of other tobacco-related cancers. Over the past several decades, the smoking prevalence has been lower in whites, but white smokers are more likely to be heavy smokers (>1 pack/day) [67]. However while smoking amount is correlated with $\mathrm{Hb}$ adduct levels up to $20 \mathrm{cpd}$, higher doses do not increase $\mathrm{Hb}$ levels further [68]. Further, blacks prefer mentholated cigarettes, which have higher machine-smoked "tar" and possibly 4-ABP concentrations than non-mentholated cigarettes. Mixed findings have been reported on differences in the association between smoking and bladder cancer risk between whites and blacks [69-71]. The present finding of racial differences in the prevalence of NAT2 phenotypes alone or in combination with CYP1A2 phenotypes may help explain these racial differences bladder cancer risk. The greater prevalence of the slow acetylation phenotype in whites may be associated with decreased 4-ABP detoxification and, thus, greater susceptibility to cell bladder cancer development as slow acetylation has been associated with elevated protein and DNA adduct levels in smokers [7,72-75], and modest increases the risk for bladder cancer $[8,76]$.

\section{Acknowledgements}

We thank Julie Cox and Daniella Scott for their efforts in subject recruiting and Steven Colosimo, Alex Fair and Faith Azuogu for their technical assistance. This work was supported by NIH grants CA68384 and K07 CA104231.

\section{R E F E R E N C E S}

[1] Madeb R, Messing EM. Gender, racial and age differences in bladder cancer incidence and mortality. Urologic Oncology 2004;22:86-92.

[2] Porter MP, Voigt LF, Penson DF, Weiss NS. Racial variation in the incidence of squamous cell carcinoma of the bladder in the United States. The Journal of Urology 2002;168: 1960-3.

[3] Castelao JE, Yuan JM, Skipper PL, Tannenbaum SR, GagoDominguez M, Crowder JS, et al. Gender- and smokingrelated bladder cancer risk. Journal of the National Cancer Institute 2001;93:538-45.

[4] IARC. IAfRoC. Tobacco Smoking. IARC monographs on the evaluation of carcinogenic risk of chemicals to humans. Lyon: IARC; 1986. p. 270.

[5] Butler MA, Iwasaki M, Guengerich FP, Kadlubar FF. Human cytochrome P-450PA (P-450IA2), the phenacetin Odeethylase, is primarily responsible for the hepatic 3demethylation of caffeine and $\mathrm{N}$-oxidation of carcinogenic arylamines. Proceedings of the National Academy of Sciences of the United States of America 1989;86:7696-700.

[6] Hein DW, Doll MA, Fretland AJ, Leff MA, Webb SJ, Xiao GH, et al. Molecular genetics and epidemiology of the NAT1 and NAT2 acetylation polymorphisms. Cancer Epidemiology Biomarkers \& Prevention 2000;9:29-42.

[7] Yu MC, Skipper PL, Taghizadeh K, Tannenbaum SR, Chan $\mathrm{KK}$, Henderson BE, et al. Acetylator phenotype, aminobiphenyl-hemoglobin adduct levels, and bladder cancer risk in white, black, and Asian men in Los Angeles, California. Journal of the National Cancer Institute 1994;86:712-6.

[8] Johns LE, Houlston RS. N-acetyl transferase-2 and bladder cancer risk: a meta-analysis. Environmental and Molecular Mutagenesis 2000;36:221-7.

[9] Kalow W, Tang BK. The use of caffeine for enzyme assays: a critical appraisal. Clinical Pharmacology 1993;53:503-14.

[10] Rasmussen BB, Brix TH, Kyvik KO, Brosen K. The interindividual differences in the 3-demthylation of caffeine alias CYP1A2 is determined by both genetic and environmental factors. Pharmacogenetics 2002;12:473-8.

[11] Nakajima M, Yokoi T, Mizutani M, Kinoshita M, Funayama M, Kamataki T. Genetic polymorphism in the $5^{\prime}$-flanking region of human CYP1A2 gene: effect on the CYP1A2 inducibility in humans. Journal of Biochemistry 1999;125:803-8.

[12] Sachse C, Brockmoller J, Bauer S, Roots I. Functional significance of a $\mathrm{C} \rightarrow \mathrm{A}$ polymorphism in intron 1 of the cytochrome P450 CYP1A2 gene tested with caffeine. British Journal of Clinical Pharmacology 1999;47:445-9.

[13] Welfare MR, Aitkin M, Bassendine MF, Daly AK. Detailed modelling of caffeine metabolism and examination of the CYP1A2 gene: lack of a polymorphism in CYP1A2 in Caucasians. Pharmacogenetics 1999;9:367-75.

[14] Schrenk D, Brockmeier D, Morike K, Bock KW, Eichelbaum M. A distribution study of CYP1A2 phenotypes among smokers and non-smokers in a cohort of healthy Caucasian volunteers. European Journal of Clinical Pharmacology 1998;53:361-7. 
[15] Tantcheva-Poor I, Zaigler M, Rietbrock S, Fuhr U. Estimation of cytochrome P-450 CYP1A2 activity in 863 healthy Caucasians using a saliva-based caffeine test. Pharmacogenetics 1999;9:131-44.

[16] Relling MV, Lin JS, Ayers GD, Evans WE. Racial and gender differences in $\mathrm{N}$-acetyltransferase, xanthine oxidase, and CYP1A2 activities. Clinical Pharmacology and Therapeutics 1992;52:643-58.

[17] Driscoll MS, Ludden TM, Casto DT, Littlefield LC. Evaluation of theophylline pharmacokinetics in a pediatric population using mixed effects models. Journal of Pharmacokinetics and Biopharmaceutics 1989;17:141-68.

[18] Johnson JA, Herring VL, Wolfe MS, Relling MV. CYP1A2 and CYP2D6 4-hydroxylate propranolol and both reactions exhibit racial differences. The Journal of Pharmacology and Experimental Therapeutics 2000;294:1099-105.

[19] Grant DM, Tang BK, Kalow W. A simple test for acetylator phenotype using caffeine 1984. British Journal of Clinical Pharmacology 2004;58:S788-93 [S94-5; discussion].

[20] Butler MA, Lang NP, Young JF, Caporaso NE, Vineis P, Hayes $\mathrm{RB}$, et al. Determination of CYP1A2 and NAT2 phenotypes in human populations by analysis of caffeine urinary metabolites. Pharmacogenetics 1992;2:116-27.

[21] Sanderson S, Salanti G, Higgins J. Joint effects of the Nacetyltransferase 1 and 2 (NAT1 and NAT2) genes and smoking on bladder carcinogenesis: a literature-based systematic HuGE review and evidence synthesis. American Journal of Epidemiology 2007;166:741-51.

[22] Bell DA, Taylor JA, Butler MA, Stephens EA, Wiest J, Brubaker LH, et al. Genotype/phenotype discordance for human arylamine $\mathrm{N}$-acetyltransferase (NAT2) reveals a new slow-acetylator allele common in African-Americans. Carcinogenesis 1993;14:1689-92.

[23] Weber WW, Hein DW. N-acetylation pharmacogenetics. Pharmacological Reviews 1985;37:25-79.

[24] Le Marchand L, Sivaraman L, Franke AA, Custer LJ, Wilkens LR, Lau AF, et al. Predictors of N-acetyltransferase activity: should caffeine phenotyping and NAT2 genotyping be used interchangeably in epidemiological studies? Cancer Epidemiology Biomarkers \& Prevention 1996;5:449-55.

[25] Eidus L, Glatthaar E, Hodgkin MM, Nel EE, Kleeberg HH. Comparison of isoniazid phenotyping of black and white patients with emphasis on South African blacks. International Journal of Clinical Pharmacology and Biopharmacy 1979;17:311-6.

[26] Bach PH, Higgins-Opitz SB, Bima B, Leary WP. Isoniazid acetylator status of Black South African tuberculosis patients. South African Medical Journal Suid-Afrikaanse tydskrif vir geneeskunde 1976;50:1132-4.

[27] Evans DA. Ethnic differences in reactions to drugs and xenobiotics therapy. Progress in Clinical and Biological Research 1986;214:491-526.

[28] Dufour AP, Knight RA, Harris HW. Genetics of isoniazid metabolism in Caucasian Negro, and Japanese Populations. Science (New York NY) 1964;145:391.

[29] Igbokwe E, Ogunniyi AO, Osuntokun BO. Xenobiotic metabolism in idiopathic Parkinson's disease in Nigerian Africans. East African Medical Journal 1993;70:807-9.

[30] Eze LC, Obidoa O. Acetylation of sulfamethazine in a Nigerian population. Biochemical Genetics 1978;16:1073-7.

[31] Jeyakumar LH, Arowoshegbe UA, Akinyinka OO, Akinbami FO, Bababunmi EA. Acetylator status of kwashiorkor children in Ibadan (south-west Nigeria). European Journal of Drug Metabolism and Pharmacokinetics 1990;15:57-62.

[32] Hadasova E, Brysova V, Kadlcakova E. N-acetylation in healthy and diseased children. European Journal of Clinical Pharmacology 1990;39:43-7.

[33] Ladero JM, Jimenez FJ, Benitez J, Fernandez-Gundin MJ, Martinez C, Llerena A, et al. Acetylator polymorphism in
Parkinson's disease. European Journal of Clinical Pharmacology 1989;37:391-3.

[34] Ladero JM, Barquero MS, Coria F, Molina JA, JimenezJimenez FJ, Benitez J. Acetylator polymorphism in Alzheimer's disease. The European Journal of Medicine 1993;2:281-3.

[35] Ladero JM, Andres MP, Banares A, Fernandez B, Hernandez C, Benitez J. Acetylator polymorphism in rheumatoid arthritis. European Journal of Clinical Pharmacology 1993;45:279-81.

[36] Loktionov A, Moore W, Spencer SP, Vorster H, Nell T, O’Neill $\mathrm{IK}$, et al. Differences in $\mathrm{N}$-acetylation genotypes between Caucasians and Black South Africans: implications for cancer prevention. Cancer Detection and Prevention 2002;26:15-22.

[37] Kadlubar FFTG, Butler MA, Teitel CH, Massengill JP, Lang NP. Determination of carcinogenic arylamine $\mathrm{N}$-oxidation phenotype in humans by analysis of caffeine urinary metabolites. In: Mendelsohn MaA RJ, editor. Mutation and the environment. Part B. Metabolism testing methods and chromosomes. Wilmington, DE: Wiley-Liss; 1990. p. 7-114.

[38] Grant DM, Tang BK, Kalow W. A simple test for acetylator phenotype using caffeine. British Journal of Clinical Pharmacology 1984;17:459-64.

[39] Kalow W, Tang BK. Use of caffeine metabolite ratios to explore CYP1A2 and xanthine oxidase activities. Clinical Pharmacology and Therapeutics 1991;50:508-19.

[40] Yuan JM, Chan KK, Coetzee GA, Castelao JE, Watson MA, Bell DA, Wang R, Yu MC. Genetic determinants in the metabolism of bladder carcinogens in relation to risk of bladder cancer. Carcinogenesis )2008;(June) [Epub ahead of print]

[41] Garcia-Closas M, Malats N, Silverman D, Dosemeci M, Kogevinas M, Hein DW, et al. NAT2 slow acetylation, GSTM1 null genotype, and risk of bladder cancer: results from the Spanish Bladder Cancer Study and meta-analyses. Lancet 2005;366:649-59.

[42] Bell DA, Taylor JA, Paulson DF, Robertson CN, Mohler JL, Lucier GW. Genetic risk and carcinogen exposure: a common inherited defect of the carcinogen-metabolism gene glutathione S-transferase M1 (GSTM1) that increases susceptibility to bladder cancer. Journal of the National Cancer Institute 1993;85:1159-64.

[43] Engel LS, Taioli E, Pfeiffer R, Garcia-Closas M, Marcus PM, Lan $\mathrm{Q}$, et al. Pooled analysis and meta-analysis of glutathione S-transferase M1 and bladder cancer: a HuGE review. American Journal of Epidemiology 2002;156:95-109.

[44] Yu MC, Ross RK, Chan KK, Henderson BE, Skipper PL, Tannenbaum SR, et al. Glutathione S-transferase M1 genotype affects aminobiphenyl-hemoglobin adduct levels in white, black and Asian smokers and nonsmokers. Cancer Epidemiology Biomarkers \& Prevention 1995;4: 861-4.

[45] Muscat JE, Axelrad C, Ray K, Weston R, Landers C, Vaccaro $\mathrm{D}$, et al. Cholesterol screening in a community health promotion program: epidemiologic results from a biracial population. Public Health Reports 1994;109:93-8.

[46] Richie Jr JP, Carmella SG, Muscat JE, Scott DG, Akerkar SA, Hecht SS. Differences in the urinary metabolites of the tobacco-specific lung carcinogen 4-(methylnitrosamino)-1(3-pyridyl)-1-butanone in black and white smokers. Cancer Epidemiology Biomarkers \& Prevention 1997;6:783-90.

[47] Block G, Woods M, Potosky A, Clifford C. Validation of a self-administered diet history questionnaire using multiple diet records. Journal of Clinical Epidemiology 1990;43: 1327-35.

[48] Lang NP, Kadlubar FF. Aromatic and hetrocyclic amine metabolism and phenotyping in humans. Progress in Clinical and Biological Research 1991;372:33-47. 
[49] Kimura M, Yamazaki H, Fujieda M, Kiyotani K, Honda G, Saruwatari. et al. CYP2A6 is a principal enzyme involved in the hydroxylation of 1,7-dimethylxanthine, a main caffeine metabolite, in humans. Drug Metabolism and Disposition 2005;33:1361-6.

[50] Park LY, Muscat JE, Kaur T, Schantz SP, Stern JC, Richie Jr JP, et al. Comparison of GSTM polymorphisms and risk for oral cancer between African-Americans and Caucasians. Pharmacogenetics 2000;10:123-31.

[51] Yengi L, Inskip A, Gilford J, Alldersea J, Bailey L, Smith A, et al. Polymorphism at the glutathione S-transferase locus GSTM3: interactions with cytochrome P450 and glutathione S-transferase genotypes as risk factors for multiple cutaneous basal cell carcinoma. Cancer Research 1996;56:1974-7.

[52] Jahnke V, Strange R, Matthias C, Fryer A. Glutathione Stransferase and cytochrome P450 genotypes as risk factors for laryngeal carcinoma. European Archives of Otorhinolaryngology 1997;254(Suppl. 1):S147-9.

[53] Smits KM, Benhamou S, Garte S, Weijenberg MP, Alamanos $\mathrm{Y}$, Ambrosone C, et al. Association of metabolic gene polymorphisms with tobacco consumption in healthy controls. International Journal of Cancer 2004;110: 266-70.

[54] Millikan RC, Pittman GS, Newman B, Tse CK, Selmin O, Rockhill B, et al. Cigarette smoking, $\mathrm{N}$-acetyltransferases 1 and 2, and breast cancer risk. Cancer Epidemiology Biomarkers \& Prevention 1998;7:371-8.

[55] Korrapati MR, Sorkin JD, Andres R, Muller DC, Loi CM, Vesell ES, et al. Acetylator phenotype in relation to age and gender in the Baltimore Longitudinal Study of Aging. Journal of Clinical Pharmacology 1997;37:83-91.

[56] Philip PA, Gayed SL, Rogers HJ, Crome P. Influence of age, sex and body weight on the dapsone acetylation phenotype. British Journal of Clinical Pharmacology 1987;23:709-13.

[57] Asprodini EK, Zifa E, Papageorgiou I, Benakis A. Determination of $\mathrm{N}$-acetylation phenotyping in a Greek population using caffeine as a metabolic probe. European Journal of Drug Metabolism and Pharmacokinetics 1998;23:501-6.

[58] Nakajima M, Yokoi T, Mizutani M, Shin S, Kadlubar FF, Kamataki T. Phenotyping of CYP1A2 in Japanese population by analysis of caffeine urinary metabolites: absence of mutation prescribing the phenotype in the CYP1A2 gene. Cancer Epidemiology Biomarkers \& Prevention 1994;3 :413-21.

[59] Bebia Z, Buch SC, Wilson JW, Frye RF, Romkes M, Cecchetti $A$, et al. Bioequivalence revisited: influence of age and sex on CYP enzymes. Clinical Pharmacology and Therapeutics 2004;76:618-27.

[60] Lampe JW, King IB, Li S, Grate MT, Barale KV, Chen C, et al. Brassica vegetables increase and apiaceous vegetables decrease cytochrome P450 1A2 activity in humans: changes in caffeine metabolite ratios in response to controlled vegetable diets. Carcinogenesis 2000;21:1157-62.

[61] Munday R, Mhawech-Fauceglia P, Munday CM, Paonessa JD, Tang L, Munday JS, et al. Inhibition of urinary bladder carcinogenesis by broccoli sprouts. Cancer Research 2008;68:1593-600
[62] Vistisen K, Poulsen HE, Loft S. Foreign compound metabolism capacity in man measured from metabolites of dietary caffeine. Carcinogenesis 1992;13:1561-8.

[63] Probst-Hensch NM, Tannenbaum SR, Chan KK, Coetzee GA, Ross RK, Yu MC. Absence of the glutathione S-transferase M1 gene increases cytochrome P4501A2 activity among frequent consumers of cruciferous vegetables in a Caucasian population. Cancer Epidemiology Biomarkers \& Prevention 1998;7:635-8.

[64] Abu-Bakar A, Satarug S, Marks GC, Lang MA, Moore MR. Acute cadimium chloride administration induces hepatic and renal CYP2A5 mRNA, protein and activity in the mouse: involvement of transcription factor NRF2. Toxicology Letters 2004;148:199-210.

[65] Langouet S, Furge LL, Kerriguy N, Nakamura K, Guillouzo A, Guengerich FP. Inhibition of human cytochorme P450 enzymes by 1,2-dithiole-3-thione, oltipraz and its derivatives, and sulforaphane. Chemical Research in Toxicology 2000;245-52.

[66] Tassaneeyakul W, Guo LQ, Fukuda K, Ohta T, Yamazoe Y. Inhibition selectivity of grapefruit juice components on human cytochromes P450. Archives of Biochemistry and Biophysics 2000;378:356-63.

[67] Stat bite: trends in cigarette smoking among adults, 19652001. Journal of the National Cancer Institute 2004;96:506.

[68] Dallinga JW, Pachen DM, Wijnhoven SW, Breedijk A, van't Veer L, Wigbout G, et al. The use of 4-aminobiphenyl hemoglobin adducts and aromatic DNA adducts in lymphocytes of smokers as biomarkers of exposure. Cancer Epidemiology Biomarkers \& Prevention 1998;7:571-7.

[69] Harris RE, Chen-Backlund JY, Wynder EL. Cancer of the urinary bladder in blacks and whites. A case-control study. Cancer 1990;66:2673-80.

[70] Burns PB, Swanson GM. Risk of urinary bladder cancer among blacks and whites: the role of cigarette use and occupation. Cancer Causes \& Control 1991;2:371-9.

[71] Hartge P, Silverman DT, Schairer C, Hoover RN. Smoking and bladder cancer risk in blacks and whites in the United States. Cancer Causes \& Control 1993;4:391-4.

[72] Landi MT, Zocchetti C, Bernucci I, Kadlubar FF, Tannenbaum S, Skipper P, et al. Cytochrome P4501A2: enzyme induction and genetic control in determining 4aminobiphenyl-hemoglobin adduct levels. Cancer Epidemiology Biomarkers \& Prevention 1996;5:693-8.

[73] Godschalk RW, Dallinga JW, Wikman H, Risch A, Kleinjans JC, Bartsch $\mathrm{H}$, et al. Modulation of DNA and protein adducts in smokers by genetic polymorphisms in GSTM1,GSTT1. NAT1 and NAT2. Pharmacogenetics 2001;11:389-98.

[74] Bartsch H, Caporaso N, Coda M, Kadlubar F, Malaveille C, Skipper $\mathrm{P}$, et al. Carcinogen hemoglobin adducts, urinary mutagenicity, and metabolic phenotype in active and passive cigarette smokers. Journal of the National Cancer Institute 1990;82:1826-31.

[75] Airoldi L, Orsi F, Magagnotti C, Coda R, Randone D, Casetta $\mathrm{G}$, et al. Determinants of 4-aminobiphenyl-DNA adducts in bladder cancer biopsies. Carcinogenesis 2002;23:861-6.

[76] Marcus PM, Vineis P, Rothman N. NAT2 slow acetylation and bladder cancer risk: a meta-analysis of 22 case-control studies conducted in the general population. Pharmacogenetics 2000;10:115-22. 